\title{
Prevalence of musculoskeletal disorders (back, neck and shoulders' pain) among dental personnel in Jeddah - Saudi Arabia
}

\begin{abstract}
Background: Musculoskeletal disorders' (MSDs) pain is a major health problem for dental personnel, and it has a bad effect on life and works quality of dental Personnel.

Aim and Objectives: This study was conducted to determine the prevalence of neck, lower back, and shoulder pain, and its associated risk factors in Jeddah, Saudi Arabia.

Methods: A cross-sectional study was conducted including 105 dental personnel, the participants answered the questionnaire electronically, the questionnaire consist of 3 main parts, demographic questions, questions about organizing the work, and questions about working conditions.

Results: the majority of the respondents (53\%) were dentists and (82\%) were females. The most prevalent MSD during the previous 12 months was reported at the neck $(73.3 \%, n=77)$, lower back $(72.4 \%, n=76)$, and then shoulders $(70.5 \%, n=74) .(68 \%)$ of the dental personnel does their work while sitting down. (12\%) always do daily exercises and (53\%) exercise sometimes. $(25.7 \%)$ of personnel had sought medication for MSD pain during the previous 12 months.
\end{abstract}

Conclusion: There was a high prevalence of MSDs. neck, lower back, and shoulder pain among dental personnel in Jeddah, Saudi Arabia.

Keywords: MSDs, prevalence, dental personnel, KSA
Volume 9 Issue 5 - 2018

\author{
Yahya A Alogaibi,' Muneerah A Alhowaish, ${ }^{2}$ \\ Rania A Baokbah, ${ }^{2}$ Hussein Alharthy, ${ }^{3}$ \\ Abdulkarim Hatrom, ${ }^{4}$ Ali A Hassan ${ }^{5}$ \\ 'Orthodontist, Bisha Dental Center, Ministry of Health, Saudi \\ Arabia \\ ${ }^{2}$ Dental Assistant, Ministry of Health, Saudi Arabia \\ ${ }^{3}$ Pedodontist, Ministry of Health, Saudi Arabia \\ ${ }^{4}$ Orthodontist, Ministry of Health, Saudi Arabia \\ ${ }^{5}$ Professor, Department of Orthodontics, King Abdulaziz \\ University, Saudi Arabia
}

\begin{abstract}
Correspondence: Yahya A Alogaibi, Orthodontist, Bisha Denta Center, Ministry of Health, Ammar bin Yasser P.O.Box 418 Bisha 61922, Saudi Arabia, Tel +966557078181,

Emaily1010@hotmail.com
\end{abstract}

Received: September 22, 2018 | Published: October 15, 2018

\section{Introduction}

Dentistry is a demanding profession regarding concentration and precision. Each profession of the dental team, which includes (dentists, dental hygienists and, dental assistants), requires different job task, but share the same repetitive and prolonged postures, either standing or sitting which leads to back, shoulder and neck pain. Musculoskeletal disorders (MSDs) describe a series of micro traumas of bones, joints, ligaments, muscles tendons, blood vessels, and nerves that accumulate in the body and may develop into more serious injury. ${ }^{1}$ They are one of the most commonly reported work-related injuries, their severity can vary from mild periodic painful attacks to severe and chronic debilitating conditions. Musculoskeletal pain is a major occupational health concern among all dental personnel due to physiological and ergonomic factors. Possible risk factors of MSD have been classified as biomechanical, ergonomic and work factors (psychosocial risk factors due to job stress). ${ }^{2}$ "Self-recognition" of the problem is generally the first step in alerting the clinician of the need to consider changes. Dental personnel have also been advised to seek and receive education about their musculoskeletal health, injury prevention, and ergonomics to improve their working environment. ${ }^{3}$ Recent studies showed that $70 \%$ of dentists start complaining of back pain by their third year of dental school. In a study conducted in the north-eastern state of Malaysia to study the prevalence and associated factors of back pain among dental personnel, results showed that the majority of respondents were females $(79.1 \%)$ the prevalence of back pain was $(44.9 \%)$ with the highest prevalence found among dental technicians $(52.4 \%)$. The significant risk factor associated with back pain were poor posture and being a dental auxiliary. ${ }^{4}$ Musculoskeletal pain affects the quality of life of dental personnel, some may seek treatment and succeed, and others decide to change their profession, resign or seek an early retirement plan out of fear to their health. However, there is a lack of data regarding musculoskeletal pain among dental personnel in Jeddah. Hence, the need was felt to conduct a study to check the prevalence and risk factors associated with MSD among them.

\section{Materials and methods}

This is an observational cross-sectional study which is based on an electronic self-administered questionnaire that was distributed to dentists. A representative sample of around (100) of dentists was selected randomly. All eligible participants who agree to participate were requested to fill out the questionnaire on the spot. On average a questionnaire filling requires $<5$ minutes to complete. The questionnaire contained (18) questions;

1. Type of institution you are working at

2. Specialty

3. Gender

4. Age

5. Marital status

6. BMI (Body Mass Index)

7. Experience in the dental profession

8. How many patients you have seen per day?

9. How many hours do you work per day? 
10. How many days do you work per week?

11. Did you have any MSD Pain before joining the dental profession?

12. Did you feel any lower back pain in last 12 months?

13. Did you feel any neck pain in the last 12 months?

14. Did you feel any shoulder pain in last 12 months?

15. Did MSD pain Couse a reduction in activity?

16. Are you on medication for this pain?

17. Are you used to work standing or sitting during providing dental treatment? 18. Are you doing daily exercises?

\section{Population \& sample of the Study}

The study population includes all dental personnel, a random sample size (105) was selected; the following table shows their characteristics according to their personal data (Table 1). It is clear from the previous table that almost $82 \%$ of the participants were females, while $18 \%$ of them were males, and their distribution according to their ages $70.5 \%$ of them were between (24-34) years old, almost $25 \%$ of them were between (35-44) years old, almost $5 \%$ of them were more than (45) years old. And their distribution according to marital status, almost $50 \%$ of the participants were Singles, and almost $50 \%$ of them were married. And their distribution according to Body Mass INDEX, almost $54 \%$ of their body mass of (20-25), while almost $46 \%$ of their body mass more than (25). And their distribution according to the type of institution in which they work, almost $73 \%$ of them were employed in government institutions, almost $4 \%$ of them were employed in Private institutions, and almost $23 \%$ of them were Student. Finally, the distribution of the participants according to Experience in the dental profession, almost $34 \%$ of them were between (1-4) year, almost $34 \%$ of them were between (5-9) year, almost $31 \%$ of them were more than (10) year. The next figure concludes the previous results (Figure 1).

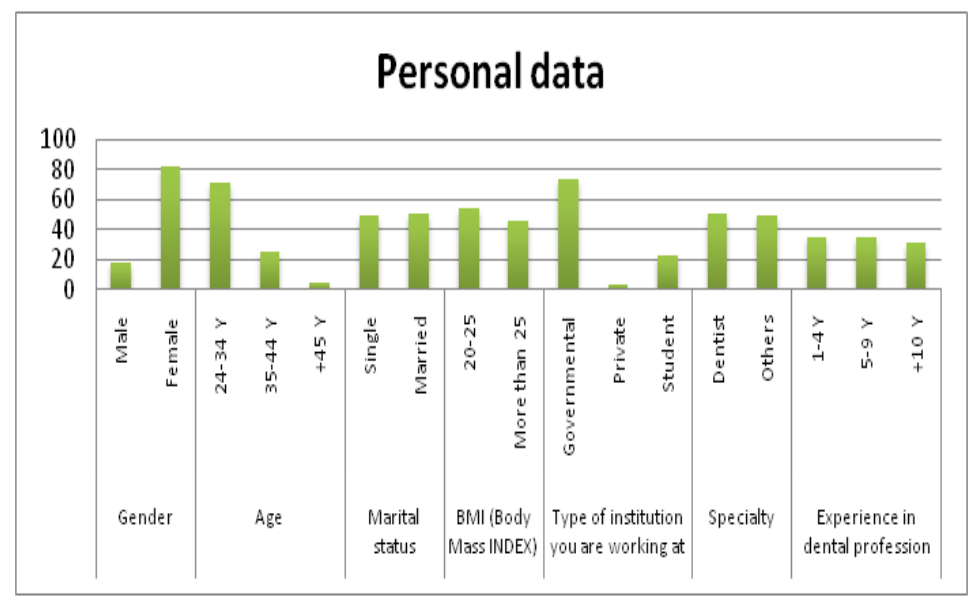

Figure I The participant's personal data.

Table I The participant's personal data $(n=105)$

Chi-squared test:**'Significant at 0.01

\begin{tabular}{lllll}
\hline Personal Data & & N. & $\%$ & P-value \\
\hline \multirow{2}{*}{ Gender } & Male & 19 & 18.1 & \multirow{2}{*}{$0.000 * *$} \\
& Female & 86 & 81.9 & \\
Age & $24-34$ Y & 74 & 70.5 & \\
& $35-44$ Y & 26 & 24.8 & $0.000 * *$ \\
Marital status & +45 Y & 5 & 4.8 & \\
\multirow{2}{*}{ BMI (Body Mass Index) } & Single & 52 & 49.5 & \multirow{2}{*}{0.922} \\
& Married & 53 & 50.5 & \\
Type of institution you are working at & $20-25$ & 57 & 54.3 & \multirow{2}{*}{0.38} \\
& More than 25 & 48 & 45.7 & \\
Specialty & Governmental & 77 & 73.3 & \\
& Private & 4 & 3.8 & $0.000 * *$ \\
& Student & 24 & 22.9 & \\
Experience in dental profession & Dentist & 53 & 50.5 & \multirow{2}{*}{0.992} \\
& Others & 52 & 49.5 & \\
& I-4Y & 36 & 34.3 & \\
& $5-9$ Y & 36 & 34.3 & 0.918 \\
& $+10 Y$ & 33 & 31.4 & \\
\hline
\end{tabular}




\section{Results}

The following table shows the participants' distribution according to the number of patients treated daily, the number of working hours per day, the number of working days per week, the situation during treatment, the daily exercise. As for the number of patients treated daily, almost $44 \%$ of dentists are treating $5-9$ patients per day; almost $24 \%$ are treating 1-4 patients per day, almost $32 \%$ Patients daily. As for daily working hours, almost $70 \%$ of dentists work more than 6 hours a day, almost $26 \%$ work $4-6$ hours a day, almost $5 \%$ work $1-3$ hours a day. As for the number of working days per week, we note that the vast majority of dentists work (4-6) days per week. We also note that nearly two-thirds of dentists treat their patients as they sit, and almost $53 \%$ of dentists participating in the study sometimes exercise (Table 2).

Table 2 Shows the participants' distribution according to the number of patients treated daily, the number of working hours per day, the number of working days per week, the situation during treatment, the daily exercise Chi-squared test:**Significant at 0.01

\begin{tabular}{|c|c|c|c|c|}
\hline & & N. & $\%$ & P-value \\
\hline \multirow{3}{*}{ How many patients you have seen per day? } & $\mathrm{I}-4$ & 25 & 23.8 & \multirow{3}{*}{$0.042 *$} \\
\hline & $5-9$ & 46 & 43.8 & \\
\hline & 10 & 34 & 32.4 & \\
\hline \multirow{3}{*}{ How many hours do you work per day? } & $\mathrm{I}-3 \mathrm{H}$ & 5 & 4.8 & \multirow{3}{*}{$0.000 * *$} \\
\hline & $4-6 \mathrm{H}$ & 27 & 25.7 & \\
\hline & $+6 \mathrm{H}$ & 73 & 69.5 & \\
\hline \multirow{3}{*}{ How many days do you work per week? } & $\mathrm{I}-3$ & 3 & 2.9 & \multirow{3}{*}{$0.000 * *$} \\
\hline & $4-6$ & 94 & 89.5 & \\
\hline & 6 & 8 & 7.6 & \\
\hline \multirow{2}{*}{ Are you used to work standing or sitting during providing dental treatment? } & standing & 33 & 31.4 & \multirow{2}{*}{$0.000 * *$} \\
\hline & sitting & 72 & 68.6 & \\
\hline \multirow{3}{*}{ Are you doing daily exercises? } & Always & 13 & 12.4 & \multirow{3}{*}{$0.000 * *$} \\
\hline & Sometimes & 56 & 53.3 & \\
\hline & Rare & 36 & 34.3 & \\
\hline
\end{tabular}

Table 3 shows the participants' distribution according to: whether they have any MSD pain before joining the dental profession, whether they feel any lower back pain in last 12 months, whether they feel any neck pain in last 12 months, whether they feel any shoulder pain in last 12 months, whether MSD pain Couse a reduction in activity, and whether they are taking medication for this pain Chi-squared test:**Significant at 0.01

\begin{tabular}{|c|c|c|c|c|c|}
\hline & \multicolumn{2}{|c|}{ Yes } & \multicolumn{2}{|l|}{ No } & \multirow{2}{*}{ P-value } \\
\hline & N. & $\%$ & N. & $\%$ & \\
\hline Did you have any MSD Pain before joining the dental profession? & 19 & 18.1 & 86 & 81.9 & $0.000^{* *}$ \\
\hline Did you feel any lower back pain in the last 12 months? & 76 & 72.4 & 29 & 27.6 & $0.000^{* *}$ \\
\hline Did you feel any neck pain in the last 12 months? & 77 & 73.3 & 28 & 26.7 & $0.000^{* *}$ \\
\hline Did you feel any shoulder pain in the last 12 months? & 74 & 70.5 & 31 & 29.5 & $0.000^{* *}$ \\
\hline Did MSD pain Couse a reduction in activity? & 60 & 57.1 & 45 & 42.9 & 0.143 \\
\hline Are you on medication for this pain? & 27 & 25.7 & 78 & 74.3 & $0.000 * *$ \\
\hline
\end{tabular}

The following table shows the participants' distribution according to: whether they have any MSD pain before joining the dental profession, whether they feel any lower back pain in last 12 months, whether they feel any neck pain in last 12 months, whether they feel any shoulder pain in last 12 months, whether MSD pain Couse a reduction in activity, and whether they are taking medication for this pain.

The majority of participants did not have any MSD Pain, while $72 \%$ felt low back pain during the past 12 months, $73 \%$ felt neck pain in last 12 months, $71 \%$ felt pain in the shoulder in last 12 months, $57 \%$ believe that back pain reduces activity, and $74 \%$ do not take medication for back pain (Table 3).

\section{Relationships test}

(Table 4) \& (Table 5) We conclude from the previous table that there is no relationship between neck pain and gender, age, body mass index, years of dental experience, daily working hours, number of patients treated daily, and method of treatment. 
Table 4 The relationship between lower back pain and (gender, age, BMI, Experience, working hours, Number of patients, and Method of treatment)

\begin{tabular}{|c|c|c|c|c|}
\hline \multirow[t]{2}{*}{ Variable } & & \multicolumn{2}{|c|}{$\begin{array}{l}\text { Did you feel any lower back pain in the } \\
\text { last } 12 \text { months? }\end{array}$} & \multirow[t]{2}{*}{ P-value } \\
\hline & & Yes & No & \\
\hline \multirow{2}{*}{ Gender } & Male & 13 & 6 & .670 \\
\hline & Female & 63 & 23 & \\
\hline \multirow{3}{*}{ Age } & $24-34 Y$ & 54 & 20 & .818 \\
\hline & $35-44 Y$ & 19 & 7 & \\
\hline & $+45 Y$ & 3 & 2 & \\
\hline \multirow[b]{2}{*}{ BMI } & $20-25$ & 39 & 18 & .323 \\
\hline & $\begin{array}{l}\text { More than } \\
25\end{array}$ & 37 & II & \\
\hline \multirow{3}{*}{ Experience in dental profession } & $\mathrm{I}-4 \mathrm{Y}$ & 26 & 10 & .842 \\
\hline & $5-9 Y$ & 25 & II & \\
\hline & $+10 Y$ & 25 & 8 & \\
\hline \multirow{3}{*}{ How many hours you work per day } & $\mathrm{I}-3 \mathrm{H}$ & 4 & 1 & .206 \\
\hline & 4-6 H & 16 & II & \\
\hline & $+6 \mathrm{H}$ & 56 & 17 & \\
\hline \multirow{3}{*}{ How many patients you have seen per day? } & 0I-Apr & 19 & 6 & .832 \\
\hline & 05-Sep & 32 & 14 & \\
\hline & 10 & 25 & 9 & \\
\hline \multirow{2}{*}{$\begin{array}{l}\text { Are you used to work standing or sitting during providing } \\
\text { dental treatment }\end{array}$} & standing & 26 & 7 & .320 \\
\hline & sitting & 50 & 22 & \\
\hline
\end{tabular}

Table 5 The relationship between neck pain and (gender, age, BMI, Experience, working hours, Number of patients, and Method of treatment)

\begin{tabular}{|c|c|c|c|c|}
\hline \multirow[t]{2}{*}{ Variable } & & \multicolumn{2}{|c|}{$\begin{array}{l}\text { Did you feel any neck pain in the last } 12 \\
\text { months? }\end{array}$} & \multirow[t]{2}{*}{ P-value } \\
\hline & & Yes & No & \\
\hline \multirow{2}{*}{ Gender } & Male & 12 & 7 & \multirow{2}{*}{.268} \\
\hline & Female & 65 & 21 & \\
\hline \multirow{3}{*}{ Age } & $24-34 Y$ & 55 & 19 & \multirow{3}{*}{.218} \\
\hline & $35-44 Y$ & 20 & 6 & \\
\hline & $+45 Y$ & 2 & 3 & \\
\hline \multirow[b]{2}{*}{ BMI } & $20-25$ & 43 & 14 & \multirow[b]{2}{*}{.595} \\
\hline & $\begin{array}{l}\text { More than } \\
25\end{array}$ & 34 & 14 & \\
\hline \multirow{3}{*}{ Experience in dental profession } & $\mathrm{I}-4 \mathrm{Y}$ & 26 & 10 & \multirow{3}{*}{.961} \\
\hline & $5-9 Y$ & 27 & 9 & \\
\hline & $+10 Y$ & 24 & 9 & \\
\hline \multirow{3}{*}{ How many hours you work per day } & $\mathrm{I}-3 \mathrm{H}$ & 5 & 0 & \multirow{3}{*}{.178} \\
\hline & 4-6 H & 17 & 10 & \\
\hline & $+6 \mathrm{H}$ & 55 & 18 & \\
\hline \multirow{3}{*}{ How many patients you have seen per day? } & $\mathrm{I}-4$ & 19 & 6 & \multirow{3}{*}{.927} \\
\hline & $5-9$ & 33 & 13 & \\
\hline & 10 & 25 & 9 & \\
\hline \multirow{2}{*}{$\begin{array}{l}\text { Are you used to work standing or sitting during providing dental } \\
\text { treatment }\end{array}$} & standing & 25 & 8 & \multirow{2}{*}{.704} \\
\hline & sitting & 52 & 20 & \\
\hline
\end{tabular}




\section{Discussion}

MSD pain is common among dental personnel with various factors increasing its prevalence. Dental professionals exhibit an elevated risk of acquiring MSDs in comparison with other professions, because of prolonged maintenance of static postures and use of precise hand and wrist movements as noted by Alexandre et al. ${ }^{5}$ \& Suneetha. ${ }^{6}$ In America, Valachi B \& Valachi $\mathrm{K}^{7}$ reported that approximately $80 \%$ of dentists complained of neck, shoulder, and lower back pain. The present study focused on the dental personnel involved in dental work, which shows the high prevalence of musculoskeletal complaints among them during the previous 12 months in Jeddah, Saudi Arabia. The majority of respondents in this study were female; age group between (24-34) years old comprised the largest proportion. The most frequently affected body sites in the present study were the neck $(73.3 \%, \mathrm{n}=77)$, lower back $(72.4 \%, \mathrm{n}=76)$, and then shoulders $(70.5 \%$, $\mathrm{n}=74)$. The prevalence data from the present study was comparable to that reported from a study of MSD among dentists in the Ha'il Region in the result of lower back rates $(73.5 \%)$ and higher than the neck $(66 \%)$, and shoulders $(43.3 \%)$ rates. ${ }^{8}$ The prevalence of lower back pain $(72 \%)$ in the current study was less than reported by dentists in Saudi Arabia $(79.1 \%)^{9}$ but higher than a survey of Taiwanese $(66 \%)^{10}$ Danish $(59 \%)^{11}$ Brazilian $(58.4 \%)^{12}$ and Australian $(53.7 \%)^{13}$ dentists. The 12-month period prevalence of neck-related pain among Jeddah dental personnel (73\%) was higher than reported by dentists in Denmark $(65 \%)^{11}$ and Saudi Arabia $(63.7 \%)^{9}$ but similar that reported by dentists in Taiwan (72\%). ${ }^{11}$ The analysis of the data from the present study of the prevalence of shoulder pain $(70.5 \%)$ was found to be less prevalent than Taiwanese $(75 \%)^{8}$ and more were reported in Brazil
(40\%). ${ }^{12}$ Studies have shown that MSDs symptoms increase with age as older dentists have spent more time with patients and eventually experience complicated pain. ${ }^{14}$ Furthermore, older dentists are more specialized with less load of patients; younger dentists are mainly practicing general dentistry or going through postgraduate training that put them under more pressure. In some previous studies, younger and less experienced dentists were more likely to report MSDs of the neck, back, and shoulders. ${ }^{15}$ In this regard, an investigation of Thai dentists revealed that less experienced dentists were more likely to suffer from musculoskeletal pain than their more experienced counterparts. ${ }^{16}$ In addition, a study by Leggat et al. ${ }^{17}$ noted that age was found to be a significant factor for back pain. They noted that back pain was more common among younger dentists. ${ }^{17}$ This could be referred to inexperience in work and inadequate knowledge in dental procedures among the younger dentists. This was not observed in this study of dental personnel in Jeddah, Saudi Arabia. However, in Leggat et al. ${ }^{17}$ study, there was no correlation between the frequency of symptoms and the age. This is compatible with the Alberta study that showed there was no association between back pain and age. ${ }^{18}$ In this case, it may be reasonable to assume that both older and younger dental personnel have the same types of postural problems. In concern to non- association between gender and MSD pain, the current study finding was compatible with that of Al Wazzan et al. ${ }^{9}$ and Shrestha et al. ${ }^{19}$ Conversely, a study by Abduljabbar TA. ${ }^{20}$ reported that female dentists had a significantly higher frequency of pain, headache and weakness than their male counterparts did. This might be explained because male usually have a higher threshold of tolerance than female (Table 6). ${ }^{20}$

Table 6 The relationship between shoulder pain and (gender, age, BMI, Experience, working hours, Number of patients, and Method of treatment)

\begin{tabular}{|c|c|c|c|c|}
\hline \multirow{2}{*}{ Variable } & & \multicolumn{2}{|c|}{$\begin{array}{l}\text { Did you feel any shoulder pain in the last } \\
12 \text { months? }\end{array}$} & \multirow{2}{*}{ P-value } \\
\hline & & Yes & No & \\
\hline \multirow{2}{*}{ Gender } & Male & 10 & 9 & \multirow{2}{*}{.06} \\
\hline & Female & 64 & 22 & \\
\hline \multirow{3}{*}{ Age } & $24-34 Y$ & 52 & 22 & \multirow{3}{*}{.252} \\
\hline & $35-44 Y$ & 20 & 6 & \\
\hline & $+45 Y$ & 2 & 3 & \\
\hline \multirow[b]{2}{*}{ BMI } & $20-25$ & 43 & 14 & \multirow[b]{2}{*}{.224} \\
\hline & $\begin{array}{l}\text { More than } \\
25\end{array}$ & 31 & 17 & \\
\hline \multirow{3}{*}{ Experience in dental profession } & $\mathrm{I}-4 \mathrm{Y}$ & 22 & 14 & \multirow{3}{*}{.314} \\
\hline & $5-9 Y$ & 27 & 9 & \\
\hline & $+10 Y$ & 25 & 8 & \\
\hline \multirow{3}{*}{ How many hours you work per day } & $\mathrm{I}-3 \mathrm{H}$ & 4 & I & \multirow{3}{*}{.14} \\
\hline & 4-6 H & 15 & 12 & \\
\hline & $+6 \mathrm{H}$ & 55 & 18 & \\
\hline \multirow{3}{*}{ How many patients you have seen per day? } & $1-4$ & 15 & 10 & \multirow{3}{*}{.421} \\
\hline & $5-9$ & 34 & 12 & \\
\hline & 10 & 25 & 9 & \\
\hline \multirow{2}{*}{$\begin{array}{l}\text { Are you used to work standing or sitting during providing } \\
\text { dental treatment }\end{array}$} & standing & 25 & 8 & \multirow{2}{*}{.422} \\
\hline & sitting & 49 & 23 & \\
\hline
\end{tabular}


BMI was not identified as a significant risk factor in this study, despite the fact that about half of the respondents were overweight or obese $(45.7 \%)$. In the Malaysian study conducted by Samat et al. ${ }^{4}$ Similar results were found, although there was no significant relationship between pain and BMI, weight control is critical in the overall health of a dental personnel, as an increase in weight increases the load on the back muscles, and maybe the cause of any subsequent pain. Although there was no correlation between BMI and MSD in this study, BMI should not be ignored as a risk factor for MSD. Conversely, a study in Norway by Heuch et al. ${ }^{21}$ on dental students reported that a high BMI was significantly associated with an increased prevalence of low back pain. ${ }^{21}$ Overweight makes the muscles highly loaded and this causes rapid development of working fatigue. ${ }^{22}$ Medical treatment and physiotherapy exercise play important role in the management of such MSD pain. The proportion of personnel seeking medication for MSD pain during our investigation $(25.7 \%)$ was less than reported during a study of dental personnel in Saudi Arabia (37\%). ${ }^{9}$ and $(37.5 \%)$ in another Study in Queensland, Australia. ${ }^{13}$ this suggests that MSD pain among dental personnel is not of a severe nature. Among the 105 study participants, $74 \%$ had never taken any treatment of their workrelated pain, which revealed ignorance in the participants. Ignorance of pain in early stage and continuous exposure to aggravating factor ultimately convert mild and moderate pain into severe disabling pain. Regular exercise was found to be effective in preventing and relieving dental work related pain. ${ }^{19}$

This study shows that the majority of the dental personnel did not perform specific exercises to prevent or minimize back, neck and shoulder pain. Harutunian et al. ${ }^{23}$ reported that aerobic activity decreases the experience of pain, assists in weight loss and strengthens the torso ${ }^{23}$ Stretching of muscles also assists in relieving back pain. Muscle relaxing exercises and rest were found to relieve the pain; while lack of exercise was strongly associated with back pain. ${ }^{24}$ Szymanska's study, however, found no significant relationship between physical activity and pain. ${ }^{25}$ There is no relationship between high prevalence of neck, back, and shoulder pain recorded in this study and various position while working. (31\%) of these worker spent working time in the standing position, which was higher than that reported by Symanska (27.6\%), ${ }^{26}$ and comparable Marklin \& Cherney ${ }^{27}$ result with $(78 \%)$ of their time spent in a seated position. In dentists in the Polat et al. ${ }^{28}$ study, standing was the preferred practice position (only $11.7 \%$ used the sitting position during working). ${ }^{28}$ It is recommended that dental personnel adopt various positions while at work. They should alternate between standing and sitting. When one does so, different sets of muscles alternate thereby allowing the other set of muscles to relax. In addition, Moradia and Patel also noted that sitting or standing for a long time was the factor that most aggravated the pain. ${ }^{28}$

In order to minimize the MSD pain problems, health promotion programs should also be carried out among the postgraduate students and the dental personnel. In addition, exercise every day, periodic break, alternating between sitting and standing positions, and frequent muscle stretching should be set as parts of the working schedule. It is helpful in preventing repetitive injuries by strengthening exercise of the affected muscles. These strategies should be known by faculty and staff and set as a policy to decrease the ongoing problems and encourage healthy behaviors throughout schools.

\section{Conclusion}

This study suggests that MSDs are considered a major occupational health problem for dental personnel in Jeddah city. Neck pain is the most common complaint followed by back pain and shoulder pain, though they all are usually mild and little proportion had sought medical attention. There was no significant difference between male and female workers with regard to musculoskeletal symptoms or any association with BMI, experience, and exercising. Additional research is now required for more carefully explain the impact of MSD on dental personnel, especially with respect to the cessation or reduction of clinical practice, moreover to identify specific risk factors and effective measures for reducing MSD among them.

\section{Recommendation}

There is a need for further studies in Saudi Arabia to establish the prevalence of MSD at a national level, indeed, to include in the survey all dental practitioners, and identify specific risk factors and effective measures for reducing MSD among them. Studies in clinical training at dental schools in Saudi Arabia should be conducted to improve teaching and clinical supervision so that MSD can be prevented.

\section{Acknowledgement}

None.

\section{Conflict of interest}

The authors declare that there is no conflict of interest.

\section{References}

1. Szeluga R. A survey of work-related musculoskeletal complaints among dental hygienists in Kentucky (unpublished manuscript). KY: Lexington; 2002:1-7.

2. Diaz-Cabellero A, Gomez-Palentia IP, Diaz Gadenas S. Ergonomic factors that cause the presence of pain muscle in students of dentistry. Med Oral Patol Oral Cir Bucal. 2010;15(6):906-911.

3. Valachi B, Valachi K. Mechanism leading to musculoskeletal disorder in clinical dentistry.Strategies to address the mechanisms leading to musculoskeletal disorders. J Am Dent Assoc. 2003;134:1604-1612.

4. Samat AR, Shafei MN, Yaacob NA, et al. Prevalence and associated factors of back pain among dental personnel in the northeastern state of Malaysia. International Journal of Collaborative Research on Internal Medicine and Public Health. 2011;3:576-586.

5. Alexandre PC, da Silva iC, de Souza LM, et al. Musculoskeletal disorders among Brazilian dentists. Arch environ Occup Health. 2011;66(4):231235 .

6. Rambabu T, Suneetha K. Prevalence of work-related musculoskeletal disorders among physicians, surgeons and dentists: a comparative study. Ann Med Health Sci Res. 2014;4(4):578-582.

7. Valachi B, Valachi K. Mechanisms leading to musculoskeletal disorders in dentistry. J Am Dent Assoc. 2003;134(10):1344-1350.

8. Lin $\mathrm{tH}$, Liu YC, Hsieh TY, et al. Prevalence of and risk factors for musculoskeletal complaints among Taiwanese dentists. J Dent Sci. 2012;7(1):65-71.

9. Al Wazzan KA, Almas K, Al Shethri SE, et al. Back and neck problems among dentists and dental auxiliaries. J Contemp Dent Pract. 2001;2(3):17-30.

10. Finsen L, Christensen H, Bakke M. Musculoskeletal disorders among dentists and variation indental work. Appl Ergon. 1998;29(2):119-125.

11. Oliveira Dantas FF, de Lima KC. The relationship between physical load and musculoskeletal complaints among Brazilian dentists. Appl Ergon. 2015;47:93-98. 
12. Aljanakh M, Shaikh S, Siddiqui AA, et al. Prevalence of musculoskeletal disorders among dentists in the Haâ [euro] (TM) il Region of Saudi Arabia. Ann Saudi Med. 2015;35(6):456-461.

13. Leggat PA, Smith DR. Musculoskeletal disorders self-reported by dentists in Queensland, Australia. Aust Dent J. 2006;51(4):324-327.

14. Soares JJF, Sundin O, Grossi G. Age, and musculoskeletal pain. Int J Behav Med. 2003;10:181-190.

15. Jacobsen N, Aasenden R, Hensten-Pettersen A. Occupational health complaints and adverse patient reactions as perceived by personnel in public dentistry. Community Dent Oral Epidemiol. 1991;19(3):155-159.

16. Chowanadisai S, Kukiattrakoon B, Yapong B, et al. Occupational health problems of dentists in southern Thailand. Int Dent J. 2000;50(1):36-40.

17. Leggat PA, Kedjarune U, Smith DR. Occupational Health Problems in Modern Dentistry. Ind Health. 2007;45(5):611-621.

18. Newell TM, Kumar S. Prevalence of Musculoskeletal Disorders among Orthodontists in Alberta. International Journal of Industria Ergonomics. 2004;33(2):99-107.

19. Shrestha BP, Singh GK, Niraula SR. Work Related Complaints among Dentists. JNMA J Nepal Med Assoc. 2008;47(170):77-81.

20. Abduljabbar TA. Musculoskeletal disorders among dentists in Saudi Arabia. Pakistan Oral \& Dental Journal. 2008;28(1):135-144.

21. Heuch I, Hagen K, Heuch I, et al. The Impact of Body Mass Index on the
Prevalence of Low Back Pain: the HUNT study. Spine.2010;35(7):764-768.

22. Polat Z, Başkan S, Altun S, et al. Musculoskeletal Symptoms of Dentists From South East Turkey. Biotechnology \& Biotechnological Equipment. 2007;21(1):86-90.

23. Harutunian K, Gargallo-Albiol J, Figueiredo R, et al. Ergonomics or musculoskeletal pain among postgraduatestudents and faculty members of the School of Dentistry of the University of Barcelona (Spain). A cross-sectional study. Med Oral Patol Oral Cir Bucal. 2011;16:e425-e429.

24. Hayes M D, Cockrell D, Smit D. A systematic review of musculoskeletal disorders among dental professionals. International Journal of Dental Hygiene. 2009; 7:159-165.

25. Szymanska S. Disorders of the musculoskeletal system among dentists from the aspect of ergonomics and prophylaxis. Ann Agric Environ Med. 2002;9:169-173.

26. Marklin RW, Cherney K. Working postures of dentists and dental hygienists. California Dental Association Journal. 2011;33(2): 133-136.

27. Polat Z, Bakan S, Altun S, et al. Musculoskeletal symptoms of dentists from South - East Turkey. Biotechnology \& Biotechnological Equipment. 2007;2(1):86-90.

28. Moradia S, Patel P. A study on occupational pain among dentists of Surat City. National Journal of Community Medicine. 2011;2(1):116-118. 